\title{
HEMODYNAMICS AT REST AND DURING EXERCISE IN NORMAL PREGNANCY AS STUDIED BY CARDIAC CATHETERIZATION ${ }^{1,2}$
}

\author{
By RICHARD A. BADER, ${ }^{3}$ MORTIMER E. BADER, ${ }^{8}$ DAVID J. ROSE, 4 AND \\ EUGENE BRAUNWALD ${ }^{5}$
}

\author{
(From the Departments of Medicine and Obstetrics, The Mount Sinai Hospital, \\ New York, N. Y.)
}

(Submitted for publication April 19, 1955; accepted June 15, 1955)

The physiological changes which take place during pregnancy are among the most extreme alterations occurring in non-pathological states. In addition to the welter of hormonal and body water changes, modifications in circulatory hemodynamics take place. Prior to the advent of cardiac catheterization, gas methods were utilized for the study of cardiac output in pregnant women (1-7). Data obtained in this manner indicated that the cardiac output increased during gestation. In general, the limitations of the gas methods for determination of cardiac output (8), i.e., their relative inaccuracy, particularly in application to exercise studies, and the inability to obtain simultaneous measurements of pressures in the right side of the heart and pulmonary artery, led to several investigations of the cardiac hemodynamics using the catheter technique (9-13).

In the studies of Palmer and Walker (9) and Hamilton (10), the catheter was placed without radiographic or fluoroscopic control into what was believed to be the right atrium. The blood obtained from the catheter was assumed to be mixed venous blood and pressures were taken with a saline manometer. Values for arterial oxygen content were assumed, thus making the $\mathrm{A}-\mathrm{V}$ oxygen difference an approximation. Werkö, Bucht, Lagerlöf, and Holmgren's $(11,13)$ careful studies did not include any observations on normal pregnant women in the mid-trimester.

No data obtained by adequate catheterization techniques are available concerning the cardiac

\footnotetext{
1 Supported by a Grant (H-1149) from the National Heart Institute of the United States Public Health Service.

2 Presented in part before the Second World Congress of Cardiology, Washington, D. C., September 1954.

3 Sara Welt Fellow.

4 Charles Klingenstein Fellow.

- Post Doctoral Research Fellow, National Heart Institute, U.S.P.H.S.
}

output and right heart pressures in normal pregnant women throughout gestation. No studies have reported the cardiac hemodynamic response to exercise in these subjects. It is the purpose of this paper to present such information.

\section{MATERIAL AND METHODS}

Cardiac catheterization was performed on 46 normal pregnant women selected from the pre-natal clinic of The Mount Sinai Hospital. History, physical examination, electrocardiogram, chest roentgenogram and fluoroscopy revealed no evidence of organic heart disease. Each patient was studied once during gestation, from the fourteenth week to one day prior to delivery at term.

The patients were divided into the following groups: Group I, 14 to 24 weeks of gestation (8 patients); Group II, 25 to 27 weeks (8 patients); Group III, 28 to 30 weeks (11 patients); Group IV, 31 to 35 weeks (9 patients) ; and Group V, 36 to 40 weeks (11 patients). No studies were performed prior to the 14th week of gestation because of the possible deleterious effects of radiation on the fetus.

With the patient in a basal, post-absorptive state, without pre-medication, catheterization of the right heart and pulmonary artery was carried out. Special care was taken to shield the patient and fetus from excess radiation. An indwelling needle was placed in the brachial artery. Pressures were recorded from the right atrium and ventricle, pulmonary artery and brachial artery and, in about one-half the cases, from the pulmonary wedge position by means of strain gauge manometers (Statham No. p 23 A) using a four channel cathode ray oscilloscopic photographic recording system. ${ }^{8}$ Cardiac output was determined by the Fick principle. Blood collected simultaneously from the pulmonary and brachial arteries was analyzed for oxygen content and capacity by the method of Van Slyke and Neill (14) with a maximum permissible difference between duplicate analyses of $\mathbf{0 . 2}$ volume per cent. Oxygen consumption was measured employing the closed system in 14 patients (Benedict Roth spirometer) and the open system in 32 patients. Expired gas was analyzed by micro Scholander tech-

- Manufactured by Electronics for Medicine, Inc., New York, N. Y. 


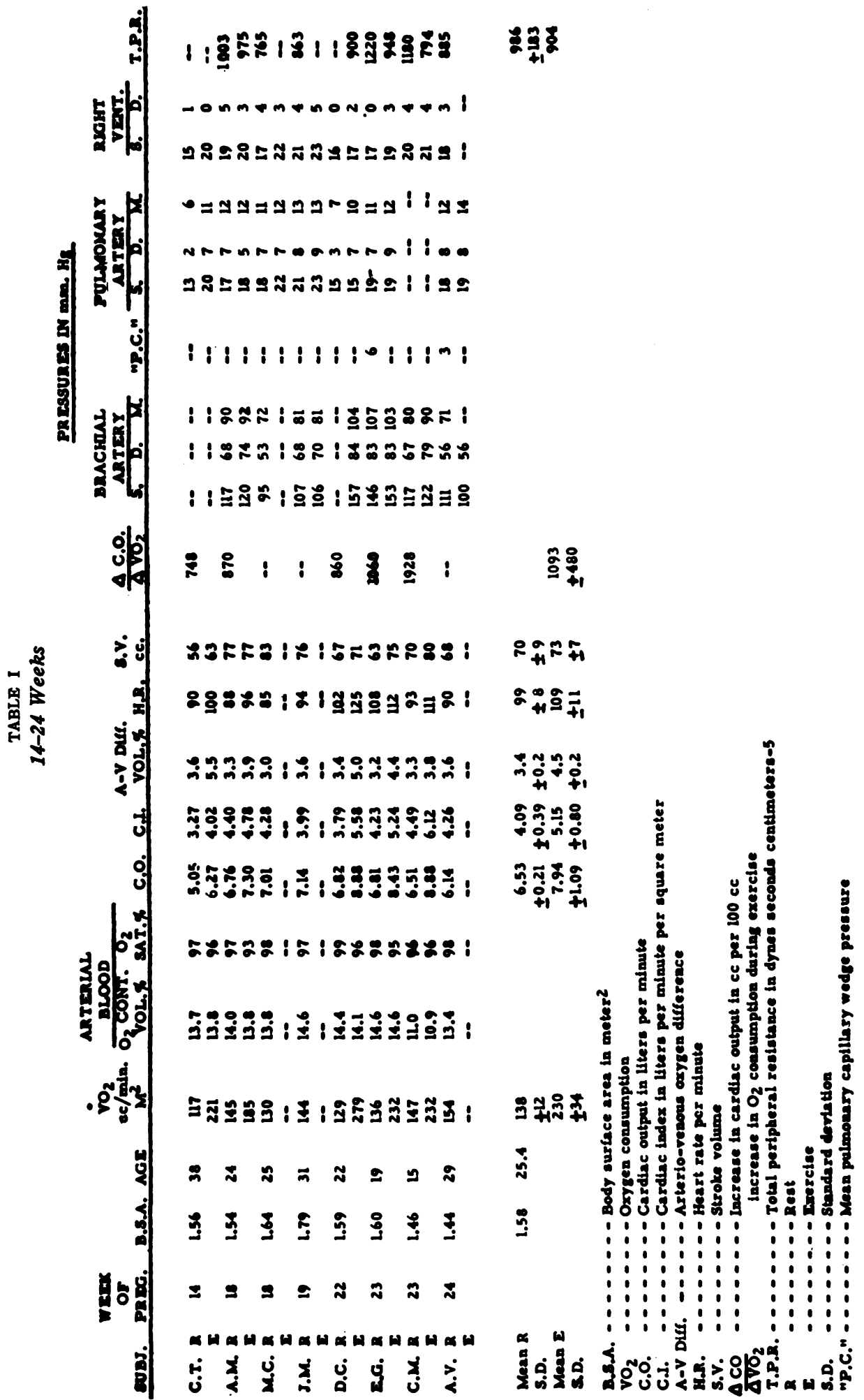




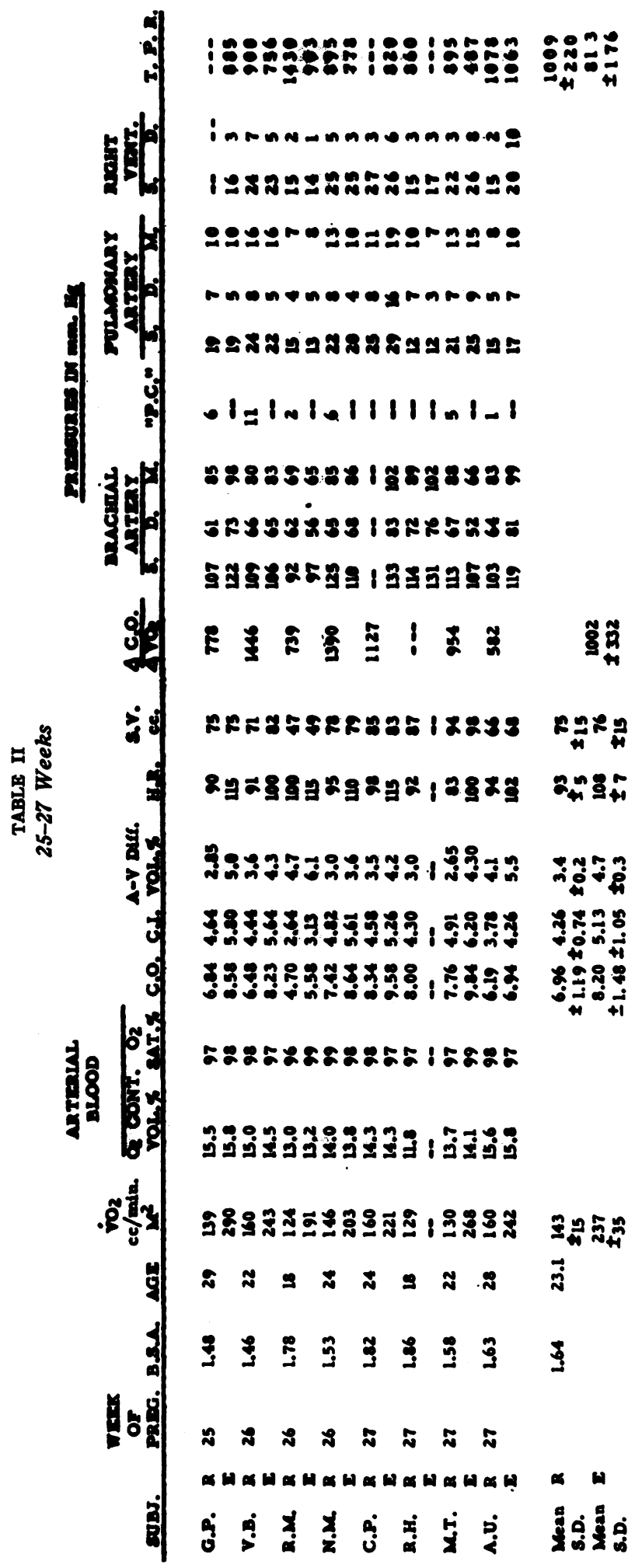




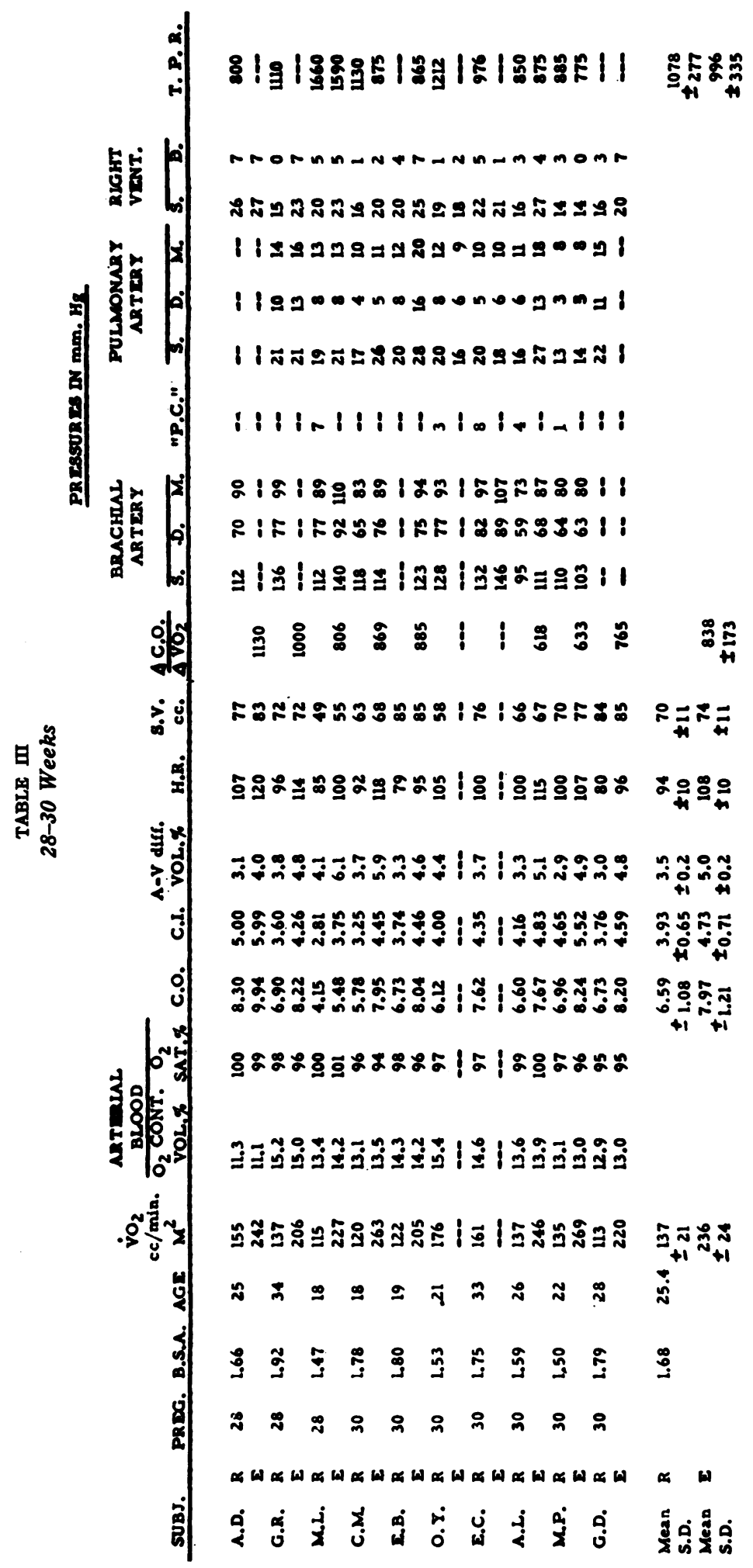




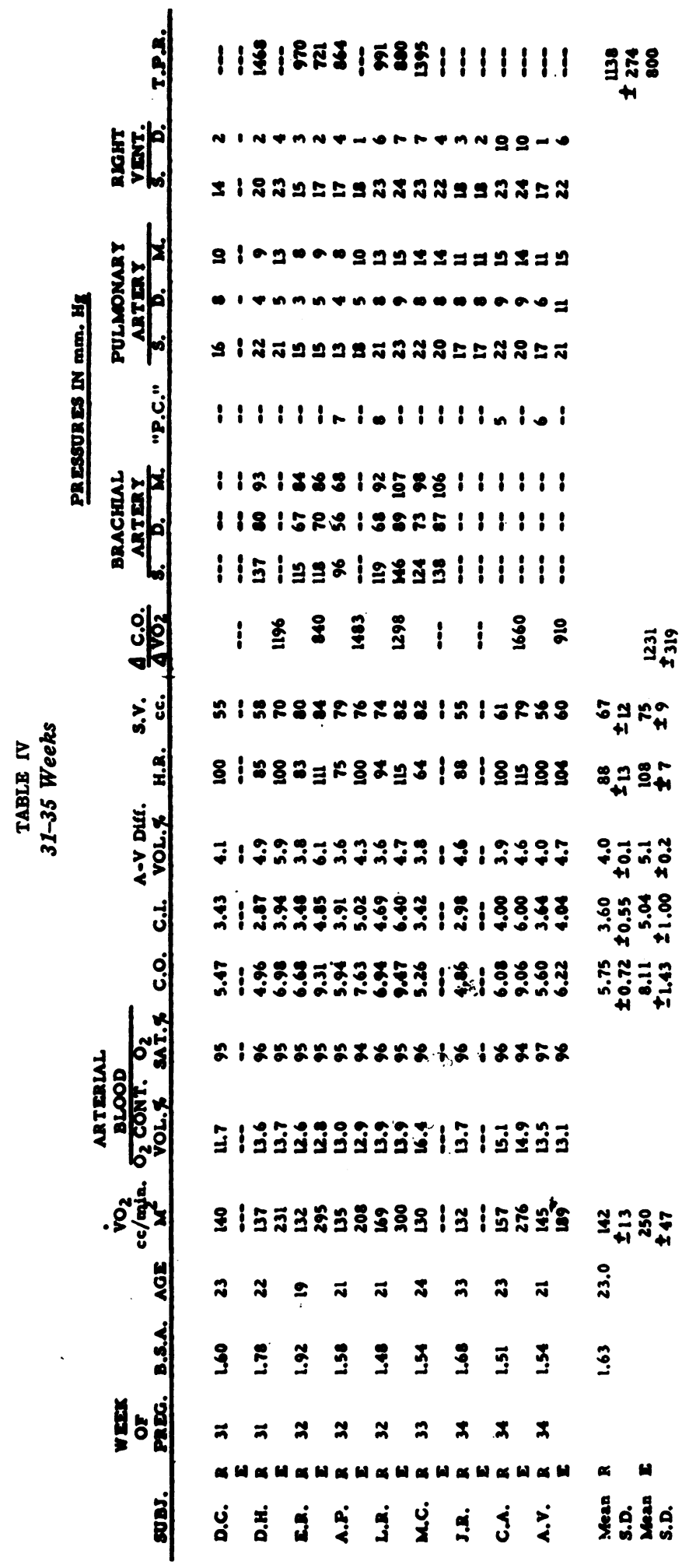




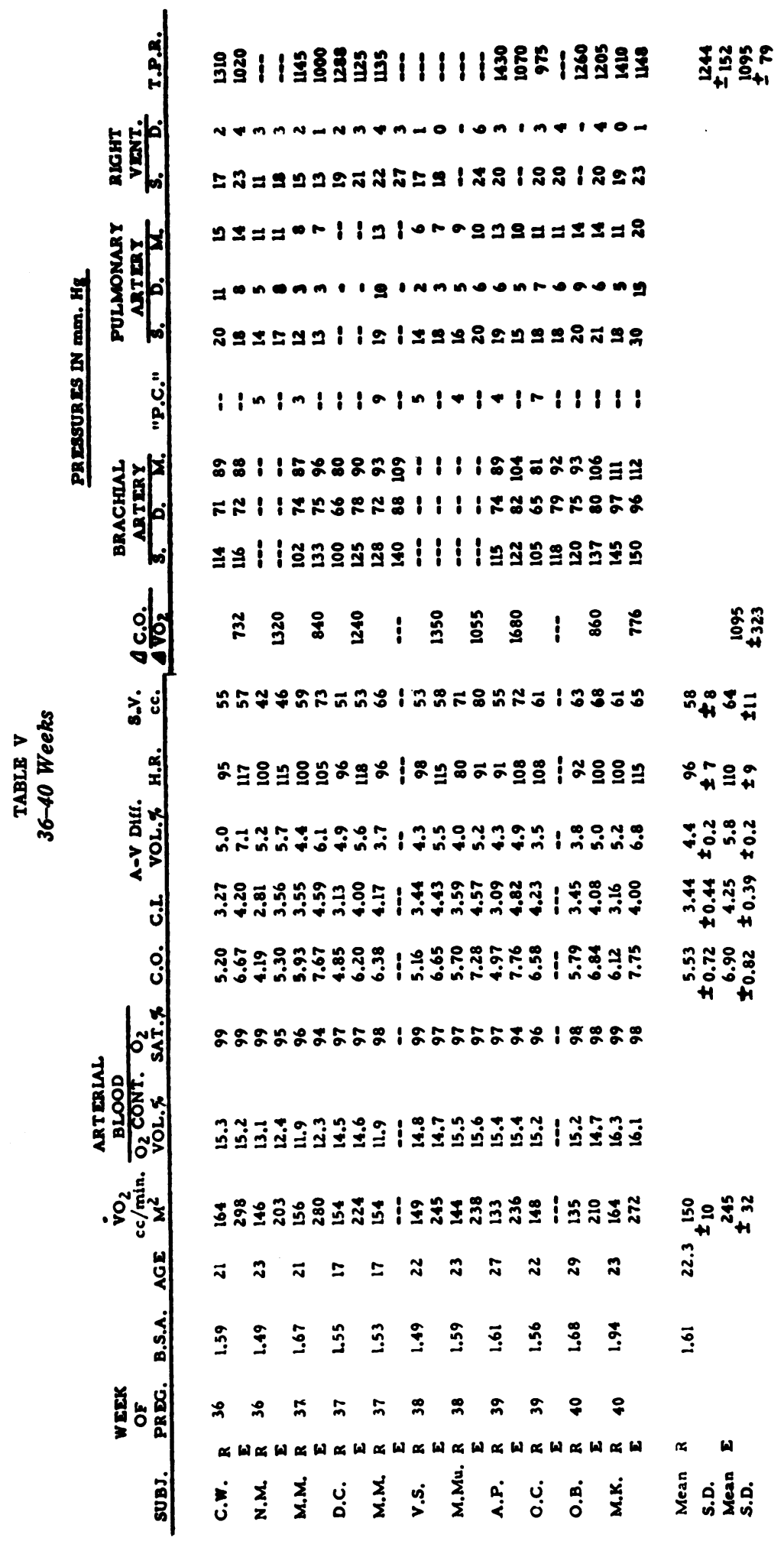


TABLE VI

Statistical data

Comparison of groups for probability of chance occurrence of difference (Groups compared)

\begin{tabular}{|c|c|c|c|c|c|c|c|c|c|c|c|}
\hline & & $\mathbf{I}-\mathbf{I I}$ & I-III & $I-I V$ & I-V & II-III & $\mathbf{I I}-\mathbf{I V}$ & $\mathbf{I}-\mathbf{V}$ & III-IV & III-V & $\boldsymbol{V}-\boldsymbol{V}$ \\
\hline V027/2 & $\mathbf{R}$ & & & & $<.05$ & & & - & & & 0.10 \\
\hline & 5 & & & & & & & & & & \\
\hline \multirow{2}{*}{$\begin{array}{l}\text { Cardiac Index } \\
\text { 1. /min. }\end{array}$} & $\mathbf{R}$ & & - & $<.10$ & 0.01 & & $<.10$ & $<, 09$ & & $<.10$ & \\
\hline & $\mathbf{E}$ & & & & .03 & & & $<.10$ & & & K.10 \\
\hline \multirow{2}{*}{$\begin{array}{l}\text { A-V O2 Diff. } \\
\text { Vol. } \%\end{array}$} & $\mathbf{R}$ & & & 6.01 & $1<02$ & & .05 & $<.02$ & & .02 & $k 10$ \\
\hline & $\mathbf{E}$ & & & & & & & & & & \\
\hline $\begin{array}{l}\text { Total Peripheral } \\
\text { Reatatance }\end{array}$ & $\mathbf{R}$ & & & & c. 10 & & & .05 & & C.10 & \\
\hline
\end{tabular}
All blank spices represent values for P > . 10 B----Brercise

nique (15) with a maximum permissible difference between duplicate analysis of 0.04 volume per cent.

Two control determinations of cardiac output were made at rest and this measurement repeated after ten minutes of exercise which consisted of pedaling a stationary bicycle in the recumbent position at a steady rate. In those instances in which the open system was used, the data presented meet the criteria for the steady state (16). Where the closed system was employed, duplicate control oxygen consumptions were required to agree within 10 per cent. Pulmonary artery pressures were measured three or four times at rest, and at 3,6, 9, and 12 minutes of exercise. Right atrial and ventricular pressures were obtained at rest and after 12 minutes of exercise. Similar control measurements of brachial artery pressure were made at rest and repeated during exercise.

Average figures for control cardiac output and pulmonary artery pressure values are presented. Peripheral resistance was calculated according to the following formula :

Peripheral Resistance

(dyne sec. $\mathrm{cm}^{-5}$ )

1,332 (mean brachial artery pressure

$=\frac{- \text { mean } \mathrm{rt} \text {. atrial pressure } \mathrm{mm} . \mathrm{Hg} \text { ) }}{\text { cardiac output }(\mathrm{ml} . / \mathrm{sec} \text {.) }}$

Statistical analysis was carried out by the non-parametric test of unpaired replicates (16A). Standard deviation was calculated separately.

\section{RESULTS}

Results including standard deviation of the mean values are presented in Tables $\mathrm{I}$ to $\mathrm{V}$. Comparison of the individual groups statistically is presented in Table VI.

\section{Oxygen consumption}

During the period of gestation studied, average oxygen consumption was found to be slightly and consistently elevated, reaching a value of 9 per cent greater than normal at term. The calculations were based on the body surface area from the standard Du Bois formula (17). Although it is recognized that this formula may not be entirely valid for the pregnant female, it is believed that the presentation of the data in terms of body surface area offers a more meaningful basis of comparison of the various groups than absolute values. $^{7}$ The increments in oxygen consumption during exercise, while differing slightly in the various groups, were in general comparable (Tables I to VI, Figure 1).

\section{Arterio-venous oxygen difference}

There is a considerable reduction in the average $\mathrm{A}-\mathrm{V}$ oxygen difference (Figure 2 ) at rest in Groups I, II and III (14 to 30 weeks) with a gradual return towards normal in the last ten weeks of gestation. In Group I (14 to 24 weeks), the average $\mathrm{A}-\mathrm{V}$ oxygen difference at rest was only 3.4 volumes per cent. It remained at approximately this level in Groups II and III, then increased in Group IV ( 31 to 35 weeks) to 4.0 volumes per cent. In Group V (36 to 40 weeks), it reached its highest level : 4.4 volumes per cent,

\footnotetext{
7 The $\mathrm{Du}$ Bois Formula for body surface area is
}

$$
\text { Area (cm. } \left..^{2}\right)=\text { wt. }{ }^{0.125} \times \text { ht. } 0.725 \times 71.84 .
$$

It is apparent that changes in weight alone as take place in pregnancy influence surface area to a lesser extent than height. The use of data reduced to square meter of body surface area is essential, since serial studies on the same patient could not be carried out, and comparisons of groups of patients studied at various stages of pregnancy were therefore necessary. 


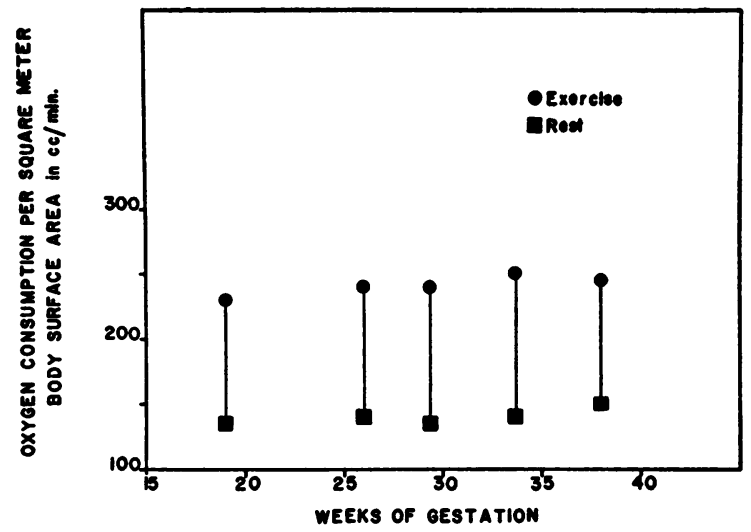

Figure 1

a normal value. During exercise, a variable increase in the average $A-V$ oxygen difference occurred, but the absolute level of $\mathrm{A}-\mathrm{V}$ oxygen difference was somewhat lower in Groups I to IV as compared with the patients studied just prior to term.

\section{Cardiac output}

It follows from the data presented above that the average resting cardiac output was elevated in Groups I, II and III, and reached its peak during the 25th to 27 th weeks of gestation. Later in pregnancy (Groups IV and V), the average resting cardiac output fell toward normal, reaching its lowest level at the 36th to 40th weeks (Figure 3). During exercise, the increase in cardiac output per hundred cubic centimeter increment in oxygen consumption was within established normal limits (18), in all but one case which was only slightly below the lower limit of normal (Figure 4).

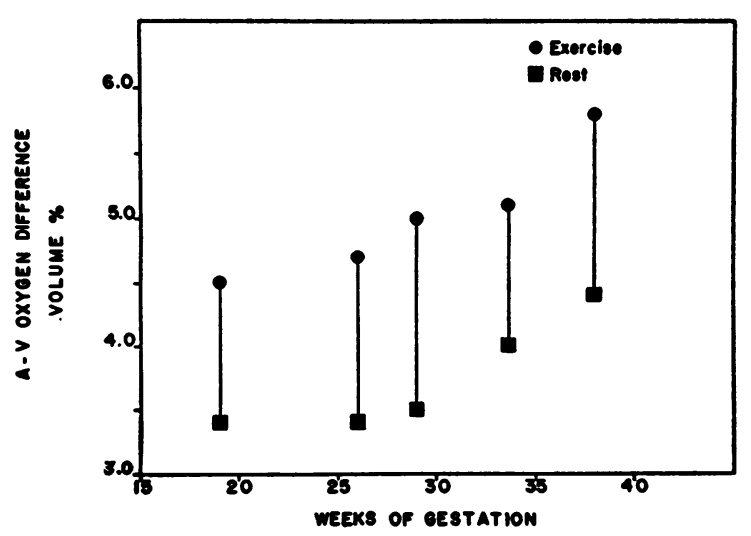

Figure 2

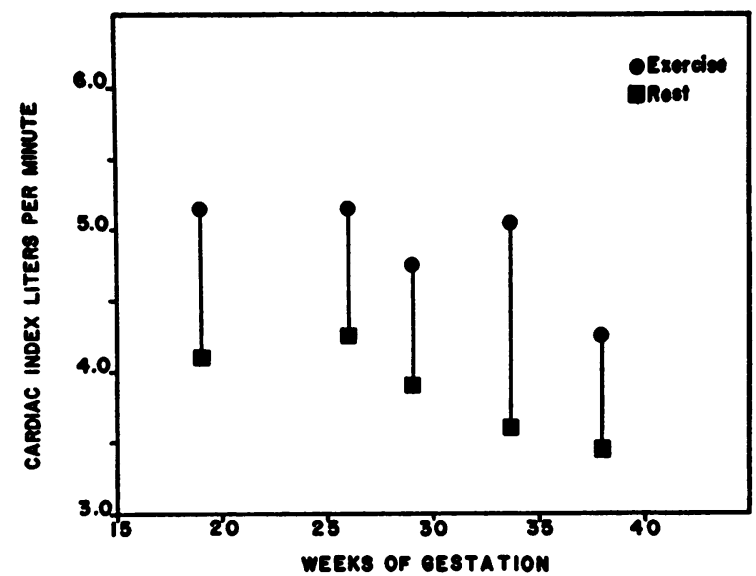

Figure 3

\section{Peripheral resistance}

No remarkable change in the systemic arterial pressure was noted during the course of gestation. It follows, therefore, from the increase in cardiac output that a decrease in peripheral resistance must take place. During the 14th to 24th weeks of gestation, the lowest average values for peripheral resistance at rest were obtained (980 dyne sec. $\mathrm{cm}^{-5}$ ). As pregnancy advanced, the peripheral resistance rose progressively, reaching a normal value of 1240 dyne sec. $\mathrm{cm}^{-5}$ at term (Figure 5).

\section{Pressures}

Pulmonary arterial and right ventricular systolic pressures at rest were within normal limits. During exercise, a slight but definite elevation was noted in all five groups. Pulmonary arterial and

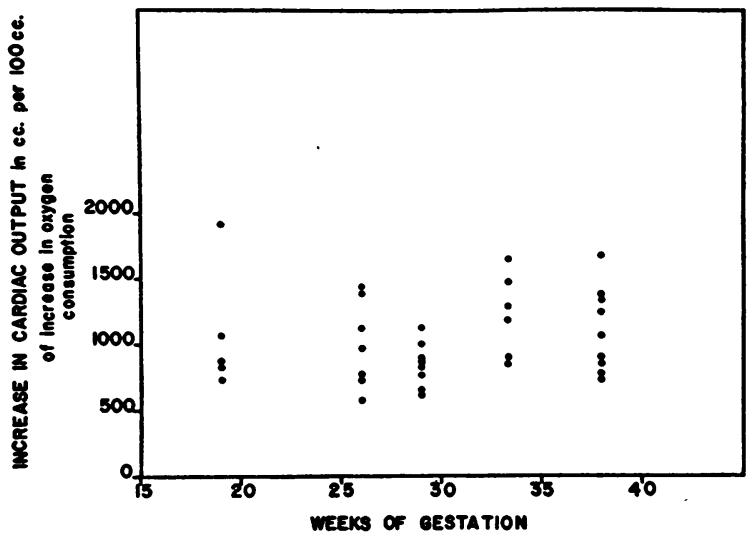

Figure 4 


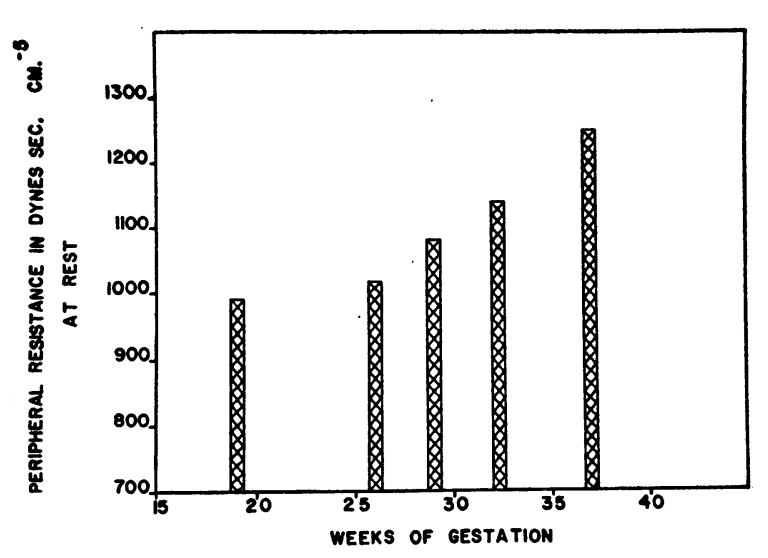

Figure 5

right ventricular systolic pressures during exercise did not exceed $30 \mathrm{~mm}$. $\mathrm{Hg}$ in any subject. Pulmonary arterial diastolic pressure was within normal limits at rest and increased slightly during exercise, exceeding $12 \mathrm{~mm}$. $\mathrm{Hg}$ in 5 subjects. Mean pressure in the pulmonary artery was within normal range (Figure 6). During exercise, it rose above $15 \mathrm{~mm}$. $\mathrm{Hg}$ in 6 subjects, reaching a level of $20 \mathrm{~mm}$. $\mathrm{Hg}$ in two; the remaining cases showed only a slight increment over resting values. "Pulmonary capillary" pressure was within normal limits. No remarkable trends were noted in right ventricular systolic, pulmonary arterial systolic, diastolic and mean, and "pulmonary capillary" pressures as pregnancy progressed.

The level of right ventricular end diastolic pressure, appears to be related to the period of gestation (Figure 7). In Groups I and V, the right ventricular end diastolic pressure was not above the upper limit of normal at rest. However,

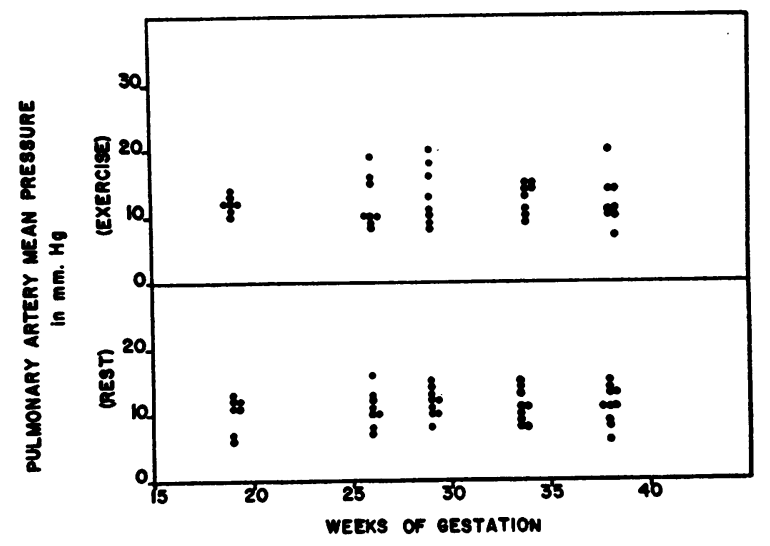

Figure 6 in patients in Groups II, III and IV (25 to 35 weeks), a definite elevation of the right ventricular end diastolic pressure was noted. The pressure exceeded $5 \mathrm{~mm}$. $\mathrm{Hg}$ in 6 of 27 subjects at rest and 9 of 24 subjects during exercise.

\section{DISCUSSION}

\section{Cardiac output}

Prior to the use of the cardiac catheter for the determination of the cardiac output in pregnancy by the Fick technique, several observers employing indirect gas methods found a variable increase of 30 to 85 per cent in the resting cardiac output during gestation (1-7). Burwell, Strayhorn, Flickinger, Corlette, Bowerman, and Kennedy

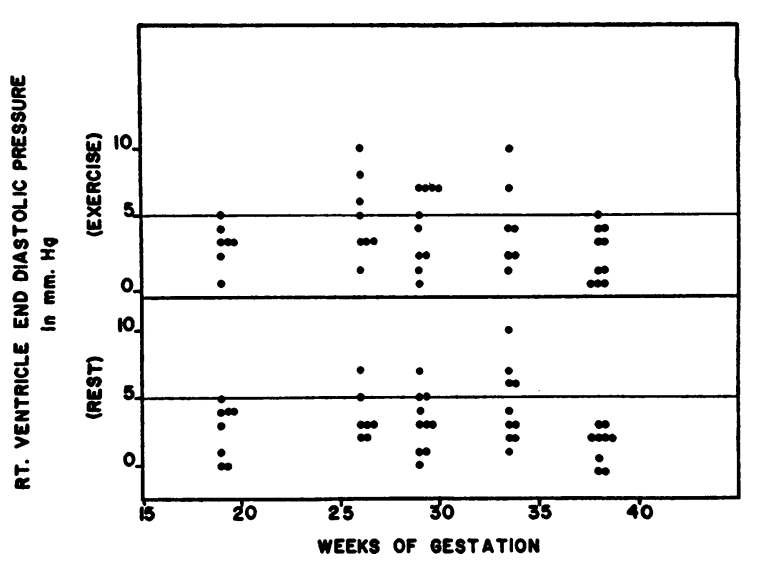

Figure 7

utilized the foreign gas technique and performed serial studies in 4 patients throughout gestation (7). While the gas techniques have their recognized limitations (8), these serial studies illustrated an increased cardiac output with a fall toward normal prior to term. Use of the dye dilution method for determination of cardiac output has also demonstrated the changes in cardiac output noted above (19). The technical methods employed in earlier cardiac catheterization studies $(9,10)$ make the interpretation of the cardiac output data difficult (13). In Werkö, Bucht, Lagerlöf, and Holmgren's studies $(11,13)$, a maximum increase in cardiac output of only 20 per cent was noted, but observations were made only early and late in pregnancy, not during the periods in which we found the maximum changes in cardiac output to take place. The present study demonstrates 
that the average resting cardiac output is increased to approximately 40 per cent greater than normal values during the 25 th to 27 th weeks of gestation, falling to normal just prior to term.

Three possible mechanisms may be invoked to account for the alterations in cardiac output during pregnancy. These are: 1) Increased metabolic demands of pregnancy; 2) hemodynamic effects of hypervolemia; and 3 ) circulatory adjustments secondary to an arterio-venous shuntlike effect of the placental circulation.

Increased metabolic demands of pregnancy. Were the increased cardiac output related primarily to increased metabolic demands of pregnancy, this should be reflected in a proportional increase in maternal oxygen consumption. However, in contrast to the 40 per cent maximum increase in cardiac output, the average oxygen consumption was elevated less than 10 per cent. The latter figure is in general agreement (20) or only slightly lower than the findings reported by others (21). It may be concluded that increased metabolic demands of pregnancy, as reflected in the maternal oxygen consumption, cannot primarily account for the increased cardiac output. This view is further supported by the findings of a marked reduction in the maternal $A-V$ oxygen differences associated with the elevated cardiac output.

Hemodynamic effects of hypervolemia. $\mathrm{Nu}-$ merous studies have confirmed the existence of significant hypervolemia during gestation (2227). Thomson, Hirsheimer, Gibson, and Evans (24) reported a peak increase in plasma volume in the ninth lunar month of 65 per cent, falling to a value 50 per cent greater than normal just before delivery. While this slight fall was noted, its statistical significance has been questioned (26) and the pre-parturition values are still considerably elevated. In addition, other serial studies have indicated a progressive increment in plasma volume with the maximum at term $(25,27)$. Most observations agree that there is an increase of 40 to 50 per cent just before parturition.

Both experimental and clinical studies (28-33) have demonstrated that hypervolemia may be responsible for significant changes in cardiac hemodynamics. Recently, Eichna, Farber, Berger, Rader, Smith, and Albert (33) have described patients in whom hypervolemia was associated with increased cardiac output and decreased $A-V$ oxygen difference and in whom a congested circulatory state existed in the absence of primary myocardial disease. While hypervolemia may be responsible, in part, for some of the hemodynamic alterations during pregnancy, the plasma volume increase does not appear to be principally responsible for the cardiac output changes, since the output at term has returned almost to normal, while the plasma volume remains elevated 40 to 50 per cent greater than normal. The only circumstances in which the cardiac output changes could be related to alterations in plasma volume would be if prior to term a significant redistribution of blood took place, with pooling of blood in the dependent venous beds and decreased venous return to the heart. Such a decrease has been reported to take place in the last month of gestation (13). At this time, elevation of venous pressure in the lower extremities without a concomitant rise in the upper extremities has also been reported (34). Finally, the absence of elevation of right ventricular end diastolic pressure in the last month of gestation (in contrast to the distinct elevation noted in some patients during the 25th to 35 th week) would be consistent with a reduction in intrathoracic blood volume, with pooling elsewhere.

$A-V$ shunt-like effect of placenta. Burwell (35) has presented the interesting hypothesis that the placenta may behave as a modified A-V fistula, which may account for the circulatory changes in pregnancy. This was based upon the increased heart rate, slight fall in systemic diastolic pressure, increased systemic pulse pressure, higher oxygen content of uterine vein blood in pregnant bitches and the presence of a bruit over the placenta. The hemodynamic alterations from the 14th to 27th weeks reported here are consistent with the type of changes seen in arterio-venous fistula $(36,37)$. The increased venous return to the right heart associated with $\mathrm{A}-\mathrm{V}$ fistula may in part account for the increase in cardiac output noted. Furthermore, changes in the placental circulation prior to term may be responsible for a reduction in the $A-V$ shunt effect and, in turn, may account for the return of cardiac output and A-V oxygen difference towards normal just before delivery. This hypothesis is supported by the physiological observations of Barcroft, Her- 
kel, Hill, Flexner, McCarthy, and McClurkin $(38,39)$ who found that uterine vein oxygen content in the rabbit is relatively elevated until the 18 th to 20th day of gestation (comparable to the 7 th to 8th month in the human female) after which there is a reduction in uterine vein oxygen content. Morphological studies of the placenta not only have demonstrated $\mathrm{A}-\mathrm{V}$ shunt-like apparatus $(40,41)$ but have also indicated that in the last weeks of gestation progressive senescence occurs, with obliteration of portions of the maternal placental circulation (42). Further evidence for aging of the placenta is found in studies of placental tissue respiration which have demonstrated a fall in the oxygen utilization by the placenta in the last month of gestation (43).

The alterations in cardiac output in normal pregnancy do not offer conclusive information concerning their mechanism. ${ }^{8}$ However, from the considerations presented above, it would appear that while all three factors may play a role, either redistribution of blood, the senescence of a placental A-V shunt, or a combination of these factors can explain the fall in cardiac output towards normal at term. The concept of obliteration of portions of the placental circulation is supported by the findings of a decreased total peripheral resistance during the second trimester, with a progressive return towards normal at term.

\section{Right heart and pulmonary vascular pressures}

Elevation of pulmonary artery mean and diastolic pressure was observed in several patients during exercise, but the most noteworthy of the changes in pressure observed was the elevation of right ventricular end diastolic pressure in the 25 th to 35 th weeks. Three possibilities could be invoked to explain this: 1) Right heart failure; 2) intrapleural pressure changes; and 3 ) effects of hypervolemia.

Elevation of the right ventricular end diastolic

8 In considering the possible role of the anemia of pregnancy on the cardiac output (44), it should be noted that in spite of the moderate reduction in hemoglobin, the total red cell mass in pregnancy is actually increased (25). In this study, the oxygen capacity averaged 14.7 volumes per cent. This moderate reduction in hemoglobin was practically uniform throughout gestation and no correlation with the degree of the anemia and level of cardiac output could be established. pressure as measured by conventional catheter technique has been regarded as evidence of right ventricular failure. However, in our patients the presence of an increased cardiac output at rest associated with a markedly decreased $A-V$ oxygen difference, and the findings of normal increase in cardiac output per unit increment in oxygen consumption on exercise, are not consistent with this possibility. The possibility exists that elevation of the intrapleural pressure during pregnancy may account for the measured elevations in right ventricular end diastolic and pulmonary artery mean and diastolic pressures. This could be related to elevation of the diaphragm, and the return of pressures to normal during the last week of gestation may be due to descent of the fetus and diaphragm which occurs frequently at this time. However, in the absence of direct measurement of intrapleural pressure, no conclusive statement is warranted. Finally, as previously noted, a congested circulatory state not related to myocardial failure (33) and associated with an increased venous return may be associated with elevations of pressure in the right heart and lesser circulation.

\section{SUMMARY AND CONCLUSIONS}

1. Cardiac hemodynamics was studied by cardiac catheterization in 46 normal pregnant women, from 14 weeks of gestation to term.

2. Arterio-venous oxygen difference was decreased to an average of 3.4 volume per cent during the 14th to 30th weeks, increasing toward normal in the month prior to term.

3. Average resting cardiac index was elevated early in pregnancy, reaching a maximum of 4.26 L. per minute at the 25 th to 27 th weeks, falling toward normal just prior to term.

4. Pressures in the brachial artery showed no significant abnormalities and calculated total peripheral resistance at rest was decreased from the 14th to 27 th weeks, rising progressively to normal at term. Cardiac output increased normally on exercise in all but one patient.

5. Pressures measured in the right heart and pulmonary artery revealed only slight increases in pulmonary arterial pressures without significant elevations above normal. Right ventricular end 
diastolic pressure was elevated in 6 of 27 patients at rest in the 25 th to 35 th weeks.

6. The possible mechanisms for the cardiac output alterations include: (a) Increased metabolic demands of pregnancy; (b) hemodynamic effects of hypervolemia ; and (c) A-V shunt-like effect of the placenta. The possible role of each of these factors has been discussed.

\section{ACKNOWLEDGMENT}

We gratefully acknowledge the advice of Dr. Dickinson W. Richards, Jr. in preparation of this manuscript. We are indebted also to Drs. Alan F. Guttmacher and Simon Dack for their cooperation, and to Misses Elisa Lopez and Ilse Weinberg for technical assistance.

\section{REFERENCES}

1. Lindhard, J., Uber das Minutenvolum des Herzens bei Ruhe und bei Muskelarbeit. Arch. f. d. ges. Physiol., 1915, 161, 233.

2. Weiss, R., Uber die Mehrleistung des Herzens während der Schwangerschaft. Klin. Wchnschr., 1924, 3, 106.

3. Gammeltoft, S.-A., Recherches sur le débit cardiaque par minute pendant la grossesse. Compt. rend Soc. de biol., 1926, 94, 1099.

4. Stander, H. J., and Cadden, J. F., The cardiac output in pregnant women. Am. J. Obst. \& Gynec., 1932, 24, 13.

5. Schmidt, R. H., Uber die Herzarbeit in der Frühschwangerschaft in der Ruhe und nach Arbeitsversuchen. Monatschr. f. Geburtsh. u. Gynäk., 1932, 90, 83.

6. Burwell, C. S., and Strayhorn, W. D., Jr., Observations on the circulation during and after pregnancy. J. Clin. Invest., 1933, 12, 977.

7. Burwell, C. S., Strayhorn, W. D., Flickinger, D., Corlette, M. B., Bowerman, E. P., and Kennedy, J. A., Circulation during pregnancy. Arch. Int. Med., 1938, 62, 979.

8. Hamilton, W. F., Notes on the development of the physiology of cardiac output. Federation Proc., 1945, 4, 183.

9. Palmer, A. J., and Walker, A. H. C., The maternal circulation in normal pregnancy. J. Obst. \& Gynaec. Brit. Emp., 1949, 56, 537

10. Hamilton, H. F. H., The cardiac output in normal pregnancy as determined by the Cournand Right Heart Catheterization technique. J. Obst. \& Gynaec. Brit. Emp., 1949, 56, 548.

11. Werkö, L., Bucht, H., Lagerlöf, H., and Holmgren, A., Cirkulation en vid graviditet. Nord. med., 1948, 40, 1868.

12. Zimmerman, H. A., A preliminary report on intracardiac catheterization studies during pregnancy. J. Lab. \& Clin. Med., 1950, 36, 1007 (Abstract).
13. Werkö, L., Pregnancy and heart disease. Acta obst. et gynec. Scandinav., 1954, 33, 162.

14. Van Slyke, D. D., and Neill, J. M., The determination of gases in blood and other solutions by vacuum extraction and manometric measurement. I. J. Biol. Chem., 1924, 61, 523.

15. Scholander, P. F., Analyzer for accurate estimation of respiratory gases in one-half cubic centimeter samples. J. Biol. Chem., 1947, 167, 235.

16. Fishman, A. P., McClement, J., Himmelstein, A., and Cournand, A., Effects of acute anoxia on the circulation and respiration in patients with chronic pulmonary disease studied during the "steady state." J. Clin. Invest., 1952, 31, 770.

16A. Walker, H. M., and Lev, J., Statistical Inference, New York, Henry Holt \& Co., 1953, pp. 426-450.

17. Du Bois, D., and Du Bois, E. F., Clinical calorimetry. Tenth paper. A formula to estimate the approximate surface area if height and weight be known. Arch. Int. Med., 1916, 17, 865.

18. Ferrer, M. I., Harvey, R. M., Cathcart, R. T., Cournand, A., and Richards, D. W., Jr., Hemodynamic studies in rheumatic heart disease. Circulation, 1952, 6, 688.

19. Adams, J. Q., Cardiovascular physiology in normal pregnancy: Studies with the dye dilution technique. Am. J. Obst. \& Gynec., 1954, 67, 741.

20. Carpenter, T. M., and Murlin, J. R., The energy metabolism of mother and child just before and just after birth. Arch. Int. Med., 1911, 7, 184.

21. Burwell, C. S., Circulatory adjustments to pregnancy. Bull. Johns Hopkins Hosp., 1954, 95, 115.

22. Miller, J. R., Keith, N. M., and Rowntree, L. G., Plasma and blood volume in pregnancy. J. A. M. A., 1915, 65, 779.

23. Dieckmann, W. J., and Wegner, C. R., The blood in normal pregnancy. I. Blood and plasma volumes. Arch. Int. Med., 1934, 53, 71.

24. Thomson, K. J., Hirsheimer, A., Gibson, J. G., 2nd, and Evans, W. A., Jr., Studies on the circulation in pregnancy. III. Blood volume changes in normal pregnant women. Am. J. Obst. \& Gynec., 1938, 36, 48.

25. Roscoe, M. H., and Donaldson, G. M. M., The blood in pregnancy. Part II. The blood volume, cell volume and haemoglobin mass. J. Obst. \& Gynaec. Brit. Emp., 1946, 53, 527.

26. McLennan, C. E., and Thouin, L. G., Blood volume in pregnancy. A critical review and preliminary report of results with a new technique. Am. J. Obst. \& Gynec., 1948, 55, 189.

27. White, R., Symposium on haemodynamics in pregnancy. III. Blood volume in pregnancy. Tr. Edinburgh. Obst. Soc., Edinburgh M. J., 1950, 57, 14.

28. Youmans, W. B., and Huckins, A. R., Chronic venous congestion without heart failure. Differentiation from true congestive heart failure in Hemodynamics in Failure of the Circulation, Spring- 
field, Charles C Thomas, 1951, pp. 46-57. (American Lecture Series.)

29. Albert, R. E., and Smith, W. W., Hemodynamic effects of ACTH, DCA and cortisone compared with congestive heart failure. Am. J. Med., 1952 , 12, 111 (Abst.).

30. Huckabee, W., Casten, G., and Harrison, T. R., Experimental hypervolemic heart failure: Its bearing on certain general principles of heart failure. Circulation, 1950, 1, 343.

31. Wilson, J. R., Jr., and Harrison, C. R., Cardiovascular, renal, and general effects of large, rapid plasma infusions in convalescent men. J. Clin. Invest., 1950, 29, 251.

32. Gimbel, N. S., Riegel, C., and Glenn, W. W. L., Metabolic and cardiovascular studies of prolonged intravenous administration of human serum albumin. J. Clin. Invest., 1950, 29, 998.

33. Eichna, L. W., Farber, S. J., Berger, A. R., Rader, B., Smith, W. W., and Albert, R. E., Non-cardiac circulatory congestion simulating congestive heart failure. Tr. A. Am. Physicians, 1954, 67, 72.

34. Burwell, C. S., A comparison of the pressures in arm veins and femoral veins with special reference to changes during pregnancy. Ann. Int. Med., 1938, 11, 1305.

35. Burwell, C. S., The placenta as a modified arteriovenous fistula considered in relation to the circulatory adjustments to pregnancy. Am. J. M. Sc., 1938, 195, 1.

36. Cohen, S. M., Edholm, O. G., Howarth, S., McMichael, J., and Scharpey-Schafer, E. P., Cardiac output and peripheral blood flow in arteriovenous aneurysm. Clin. Sc., 1948, 7, 35.

37. Schreiner, G. E., Freinkel, N., Athens, J. W., and Stone, W., III., Cardiac output, central volume, and dye injection curves in traumatic arteriovenous fistulas in man. Circulation, 1953, 7, 718.

38. Barcroft, J., Herkel, W., and Hill, S., The rate of blood flow and gaseous metabolism of the uterus during pregnancy. J. Physiol., 1933, 77, 194.

39. Barcroft, J., Flexner, L. B., Herkel, W., McCarthy, E. F., and McClurkin, T., The utilization of oxygen by the uterus in the rabbit. J. Physiol., 1934, 83, 215.

40. Spanner, R., Mütterlicher und kindlicher Kreislauf der menschlichen Placenta und seine Strombahnen. Ztschr. f. Anat. u. Entwicklungsgesch., 1935, 105, 163.

41. Earn, A. A., and Nicholson, D., The placental circulation, maternal and fetal. Am. J. Obst. \& Gynec., 1952, 63, 1.

42. Zeek, P. M., and Assali, N. S., The formation, regression, and differential diagnosis of true infarcts of the placenta. Am. J. Obst. \& Gynec., 1952, 64, 1191.

43. Wang, H. W., and Hellman, L. M., Studies in the metabolism of the human placenta. I. Oxygen consumption in relation to aging. Bull. Johns Hopkins Hosp., 1943, 73, 31.

44. Brannon, E. S., Merrill, A. J., Warren, J. V., and Stead, E. A., Jr., The cardiac output in patients with chronic anemia as measured by the technique of right atrial catheterization. J. Clin. Invest., 1945, 24, 332. 